
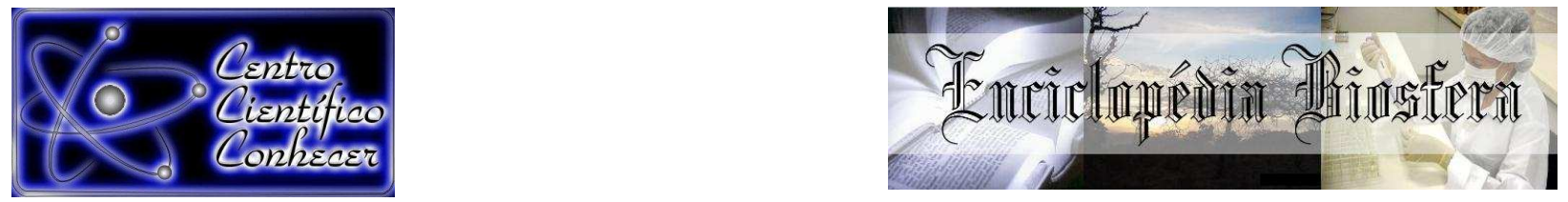

\title{
A FORMAÇÃO DE PROFESSORES DE BIOLOGIA E A TEORIA DA COMPLEXIDADE: REFLEXÕES E DESAFIOS PARA A ATUALIDADE
}

\author{
Lindomar Gomes dos Santos ${ }^{1}$, Ludmylla Ferreira de Souza Rodrigues², Márcia \\ Mendes Simão ${ }^{3}$.
}

1 Mestrando em Educação em Ciências e Matemática, Universidade Federal de Goiás (lin_gomez@hotmail.com).

2 Mestranda em Educação em Ciências e Matemática, Universidade Federal de Goiás.

3 Mestranda em Educação em Ciências e Matemática, Universidade Federal de Goiás.

Recebido em: 03/10/2016 - Aprovado em: 21/11/2016 - Publicado em: 05/12/2016 DOI: 10.18677/EnciBio_2016B_141

\begin{abstract}
RESUMO
Ainda hoje, a docência universitária baseia-se no paradigma newtoniano-cartesiano, a exemplo disso, os cursos de graduação em Biologia são organizados por disciplinas isoladas, desconexas e descontextualizadas, demonstrando a necessidade de se repensar a formação docente. Este artigo teórico tem por objetivo discutir o processo de formação de professores de biologia sob a luz da Teoria da Complexidade de Edgar Morin e sinalizar possibilidades para uma formação transdisciplinar. Morin propõe uma reforma radical do pensamento, fazendo a religação dos saberes, neste sentido, discute-se o uso dos princípios dialógico, recursivo e hologramático. E a transdisciplinaridade é apresentada como possibilidade de integração do conhecimento, podendo auxiliar o professor em formação a superar essa visão de fragmentação disciplinar.
\end{abstract}

PALAVRAS-CHAVE: Complexidade; Formação de Professores de Biologia;

Transdisciplinaridade.

\section{BIOLOGY TEACHER EDUCATION AND THE THEORY OF COMPLEXITY: REFLECTIONS AND CHALLENGES FOR THE PRESENT TIMES}

\begin{abstract}
Even today, the university teaching is based on the Newtonian-Cartesian paradigm, as an example, undergraduate courses in Biology are organized by isolated, disconnected and decontextualized subjects, demonstrating the need to rethink teacher training. This theoretical article aims to discuss the process of training of biology teachers in the light of the Complexity Theory of Edgar Morin and signal opportunities for transdisciplinary training. Morin proposes a radical reform of thought, making the reconnection of knowledge, in this sense, we discuss the use of dialogic, recursive and holographic principles. We point out transdisciplinarity as the possibility of integration of knowledge, which can assist the teacher in training to overcome this disciplinary fragmentation of vision.
\end{abstract}

KEYWORDS: Biology Teacher Training; Complexity; Transdisciplinary. ENCICLOPÉDIA BIOSFERA, Centro Científico Conhecer - Goiânia, v.13 n.24; p. 1525 


\section{INTRODUÇÃO}

A reflexão sobre a formação de professores ainda se constitui como um grande desafio, frente às exigências de um mundo contemporâneo que almeja por soluções e alternativas inovadoras e que rompam a tradição da simplificação e da fragmentação de conhecimento, na busca por um cidadão mais crítico e autônomo e provido de conhecimento pleno (GATTI, 2014).

Segundo BITTAR et al. (2011), a partir da década de 90 a produção científica da pós-graduação experimentou um novo padrão, consequência das atividades avaliativas implementadas pela CAPES, e entre os resultados da pressão exercida pelos critérios avaliativos pré-estabelecidos estão o crescimento, a diversificação e ainda a qualidade das produções. Com essa valorização e diversificação há uma erupção de situações problemáticas a serem discutidas e investigadas nas pesquisas em educação. Apesar desses estudos apontarem que a educação emerge na necessidade de entender a complexidade da realidade, o ensino observado ainda é baseado no conhecimento de informações e dados desconexos (AZEVEDO et al., 2012).

Uma das discussões que motiva os pesquisadores, entre eles MORIN (2014), é a forma como o sujeito concebe a realidade, ensino fragmentado, descontextualizado e sem sentido nenhum para o estudante. Considerando esses obstáculos, como conceber o real, aberto e complexo, a partir de ideias simplistas e objetivas? Nessa perspectiva, a Teoria da Complexidade de Edgar Morin surgiu como forma de ruptura dos paradigmas tradicionais e clássicos de ensino, apresentando-se como algo inovador e uma plenitude a ser alcançada (GEMIGNANI, 2012).

MORIN (2014) propôs uma reforma radical do pensamento, fazendo a religação dos saberes, uma vez que "o retalhamento das disciplinas torna impossível aprender o que é tecido junto, isto é, o complexo, segundo o sentido original do termo". E para tanto se torna indispensável uma mudança no processo de formação de professores, para a superação da compartimentalização do conhecimento e o desenvolvimento de habilidades para reflexões mais amplas, multidimensionais e contextualizadas, pois como pontua em sua obra $A$ cabeça bem feita, "O conhecimento só é conhecimento enquanto organização, relacionado com as informações e inserido no contexto destas" (MORIN, 2014).

NASCIMENTO \& MARTINAZZO (2008) consideram que nos cursos de formação docente há a necessidade do equilíbrio entre os saberes teórico-prático e pedagógico, proporcionando aos professores oportunidades de uma formação mais aprofundada e com o fortalecimento de competências para que estes trabalhem conteúdos de diferentes níveis adequando-os às necessidades dos estudantes e saibam realizar a devida transposição didática desses conteúdos.

Formar-se professor em concepções da teoria da complexidade, ainda se constitui nos dias atuais, uma tarefa difícil de ser alcançada, se não houverem mudanças e reformulações pedagógicas nos conteúdos, que muitas vezes são constituídos por todo um conjunto de técnicas ultrapassadas e métodos obsoletos (NASCIMENTO \& MARTINAZZO, 2008).

MORIN (2014), no livro A Cabeça bem feita, propôs uma reforma na educação, visando a superação da fragmentação dos conteúdos e abrangendo os três níveis de ensino, primário, secundário e as universidades. Quanto à reforma universitária proposta por MORIN (2014), há a intenção de superar o ensino tradicional e positivista, que separa as disciplinas umas das outras, isolando os conteúdos sem 
que seja feita a interligação, separando o todo e suas partes. Trata-se, então, de proporcionar uma formação aos docentes para que eles se eduquem e eduquem seus alunos atendendo as novas exigências e necessidades educacionais emergentes nesse novo século (NASCIMENTO \& MARTINAZZO, 2008).

Dentre os desafios da reforma proposta por MORIN (2014), está o que ele chamou de Desafio dos desafios, no qual "a reforma do ensino deve levar à reforma do pensamento e a reforma do pensamento deve levar à reforma do ensino", em um ciclo, demonstrando a interligação entre o pensamento complexo defendido por ele, com os novos anseios do ensino, cuja divisão de disciplinas em sucessivas partes já não é mais capaz de atender.

Essa variedade de disciplinas e conteúdos segmentados é bem visível em diversas áreas, como a medicina, a engenharia, o direito e na tão jovem biologia, ciência consolidada no século XX, mas igualmente herdeira do legado positivista da simplificação e da esfacelação dos saberes em quantas partes menores forem possíveis, proposta por Descartes (MORIN, 2014).

A biologia surgiu enquanto ciência dividida e guiada por disciplinas como a botânica, genética, biologia molecular, citologia, bioquímica, zoologia e diversas outras, as quais são pensadas de forma independente e autônoma, desde a grade dos cursos de formação inicial dos professores, na graduação e essa separação acabou por ser cartesianamente repetida pelos docentes já no exercício da profissão. E essa forma de ensino tem se perdurado ao longo dos anos, numa sucessão de saberes biológicos desconexos e descontextualizados entre si e do cotidiano do aluno, reproduzindo a criação de uma inteligência cega, inconsciente e irresponsável (MORIN, 2014). O que demonstra a necessidade de se repensar o processo de formação docente.

Diante do exposto é notório que a formação de professores enfrenta impasses e problemas que irão influenciar diretamente na futura prática docente (GATTI, 2014). Desse modo, o objetivo deste trabalho foi discutir o processo de formação de professores de biologia sob a luz da Teoria da Complexidade de Edgar Morin e sinalizar possibilidades para uma formação transdisciplinar.

\section{A FORMAÇÃO INICIAL DE PROFESSORES: Herança Newtoniana-Cartesiana}

O professor que se encontra em processo de formação inicial necessita ter uma visão ampla e profunda sobre a realidade de sua prática educativa, saber contextualizá-la, e bem como estar munido de instrumentos para refletir sobre o sentido da mesma. Todavia, essa gama de saberes necessários a uma reflexão, fundamental à formação inicial do professor, tem sido mal compreendida (SILVA \& INFANTE-MALACHIAS, 2012) e até mesmo negligenciada nos cursos de formação de professores.

Para MORAES (2007) "A concepção dos modelos de formação sempre estivera vinculada aos marcos teóricos e epistemológicos de determinados paradigmas que, de um modo ou de outro, predominaram nos momentos sóciohistóricos do conhecimento social".

O pensamento clássico, disjuntor e reducionista, foi responsável pelo avanço das ciências naturais no século XX, pois possibilitou entendimento de fenômenos inimagináveis, que são muito importantes para compreensão do mundo real (HOBSBAWM, 2015). Mas esse mesmo pensamento culminou na exagerada compartimentalização do conhecimento e tem seus reflexos na fragmentação presente nos currículos das licenciaturas, que hoje dificulta a compreensão do real 
em sua complexidade. Esse contexto exige mudança no perfil formativo e prática pedagógica dos professores, e para isso é necessário repensar a abordagem dos conhecimentos específicos numa perspectiva abrangente e complexa. Nesse sentido, PETRAGLIA (2011) ressalta que:

Quando pensamos na organização de um curso de graduação como um
"todo", consideraremos, então as disciplinas que o compõe como partes
integrantes e significativa, que especifica e particularmente, apresentam
suas características e qualidades individuais a visão de seus recortes são
importantes, enquanto estudo de aspectos próprios, ao mesmo tempo que
contribuem para a visão da compreensão de conjunto, na dimensão da
complexidade do ser e do saber (PETRAGLIA, 2011).

Ainda hoje, é percebido que a docência universitária baseia-se no paradigma conservador newtoniano-cartesiano, levando à fragmentação dos conceitos ensinados, uma visão reduzida de mundo, atendendo a lógica disciplinar que é cada vez mais linear e reducionista. Os alunos aprendem de maneira individual, por meio de repetições e memorização, o que impede uma visão global na conexão dos conhecimentos propostos em cada etapa do ensino aprendizagem (BEHRENS, 2012).

SILVA \& INFANTE-MALACHIAS (2012) consideram que nas últimas décadas houve uma confusa noção sobre profundidade de conhecimento, associada em geral à ideia de especialização, na qual um indivíduo sabe muito sobre um mesmo assunto particular e desconhece outros temas essenciais para o exercício da prática docente. Nessa arraigada organização de conhecimento científico, é valorizada a figura do especialista, ou seja, aquele "que sabe muito sobre quase nada"

Dentro desse contexto, SILVA et al., (2013) destacam que os cursos de formação na área das ciências biológicas ainda seguem essa proporção fragmentada positivista, projetando assim a hiperespecialização dos conhecimentos. Conteúdos como Bioquímica, Biologia Molecular e Celular, são ministrados de formas desconexas, uma vez que se torna muito difícil sua conexão e aplicação cotidiana posteriormente. Isso reflete diretamente na prática docente dos futuros professores, já que o acadêmico não conseguiu observar algo mais complexo e reflexivo na sua formação. Para MORIN (2014), "De fato, a hiperespecialização impede de ver o global (que ela é fragmentada em parcelas) bem como o essencial (que ela dilui). Ora, os problemas essenciais nunca são parceláveis, os problemas globais são cada vez mais essenciais."

Partilhando desse pensamento, ISKANDAR \& LEAL (2002) consideram que:

A educação influenciada pelos ideais positivistas carece de incentivo ao desenvolvimento do pensamento crítico. Aceitar a ciência como o único conhecimento, como queria o positivismo, é algo reducionista que perde uma considerável parcela de conhecimento que não estão no dado; fica prejudicada tanto a criação como a dedução (ISKANDAR \& LEAL, 2002, p. 5).

BEHRENS \& RODRIGUES (2014) afirmam que o paradigma newtonianocartesiano precisa ser superado, principalmente no que se refere ao papel do professor, visto que essa visão fragmentada do universo gera na educação a proposição do conhecimento baseado no pensamento simplificador que de certa forma torna-se enfatizado pela fragmentação das disciplinas, mantendo assim um currículo linear e muito reducionista. Não cabe nesta discussão culpá-lo por suas ENCICLOPÉDIA BIOSFERA, Centro Científico Conhecer - Goiânia, v.13 n.24; p. 1528 2016 
práticas conservadoras e até mesmo retrogradas, e sim sinalizar os problemas relacionados a essas práticas e se possível oportunizar a reflexão. Para BEHRENS (2012) "Neste século, torna-se indispensável que os professores e os alunos assumam o papel de produtores do conhecimento mais críticos, criativos, autônomos e transformadores dessa realidade".

\title{
ENTENDER O REAL NAS PARTES E COMPREENDER NO TODO
}

Clarice Lispector, no livro $A$ descoberta do mundo, traz uma reflexão sobre a complexidade do entendimento do real que permeia as discussões sobre a compreensão do mundo a partir das ideias da Teoria da Complexidade de MORIN (2014):

\begin{abstract}
Não entendo. Isso é tão vasto que ultrapassa qualquer entender. Entender é sempre limitado. Mas não entender pode não ter fronteiras. Sinto que sou muito mais completa quando não entendo. Não entender, do modo como falo, é um dom. Não entender, mas não como um simples de espírito. $O$ bom é ser inteligente e não entender. É uma benção estranha, como ter loucura sem ser doida. É um desinteresse manso, é uma doçura de burrice. Só que de vez em quando vem a inquietação: quero entender um pouco. Não demais: mas pelo menos entender que não entendo (LISPECTOR, 2013).
\end{abstract}

Quando a autora se refere ao entender deixa claro que ele é limitado para compreensão do mundo, ou seja, ao não entender há possibilidade de ir além através da inquietude e questionamento, e assim aprimorar as diferentes leituras do mundo. Ao entender como os fenômenos ocorrem, mas não compreender o porquê e as implicações envolvidas nesse processo, uma visão unilateral e simplificada desse fenômeno. $E$ isso pode ser incompletude que a autora se refere. Nesse sentido, MORIN (2011a) afirma que o conhecimento que almeja o todo e o busca na simplificação acaba por encontrar a complexidade no caminho, portanto na pretensão de encontrar a completude pode se deparar com a incompletude.

Segundo MORIN (2011a) a complexidade está relacionada às contradições e essa visão do real inclui a incerteza, arduamente combatida no pensamento clássico, o que assinala a impossibilidade do saber em sua totalidade e da premissa da ciência como reduto da verdade absoluta firmada nos dogmáticos pilares da certeza, da ordem, da separação e da lógica. E ciente dessa impossibilidade, o autor propõe uma nova forma de pensar o real que seja desafiadora e desafiada a apreender essa complexidade.

Essa capacidade de apreensão vem embasada no perceber e compreender bem as coisas, dada toda a complexidade e multiplicidade da realidade, para MORIN (2011a), a complexidade não pode ser contemplada nas ideias simplistas, nem tampouco reducionistas. E a partir dessa impossibilidade, o autor apresenta um pensamento que possa alcançar essa complexidade e a proposta vem alicerçada no que chama de Teoria da Complexidade.

Contudo ao fomentar um pensamento complexo relacionado à exclusão do pensamento clássico, ou seja, ao conceber o complexo a visão será inclusiva e no sentido de ampliar as possibilidades. Dentro dessa perspectiva, ao apreender a possibilidade da certeza provisória dentro de incertezas inevitáveis e da ordem aliada à desordem, chega-se a consciência do real complexo. $E$ no intuito de ajudar a pensar essa complexidade, MORIN (2011a) apresenta os princípios dialógicos, recursivo e hologramático. 
O princípio dialógico, diferente do dialético, concerne no entrelaçamento de duas lógicas que aparentemente estão separadas. Ou seja, juntar o que seria pensado separado, devido à natureza antagônica, ao considerar impossível a disjunção entender um fenômeno complexo (MORIN, 2014). Para ilustrar a possibilidade de pensar o complexo a partir do princípio dialógico, o autor afirma que:

\begin{abstract}
Deve-se conceber uma dialógica ordem/desordem/organização, desde o nascimento do Universo: a partir de uma agitação calorífica (desordem), onde, em certas condições (encontros aleatórios), princípios de ordem vão permitir a constituição de núcleos, átomos, galáxias e estrelas. Sob as mais diversas formas, a dialógica entre a ordem, a desordem e a organização via inúmeras inter-retroações, está constantemente em ação nos mundos físico, biológico e humano (MORIN, 2014).
\end{abstract}

No paradigma clássico é explicita a visão linear da causa-efeito, de que a causa "a" gera o efeito "b", o determinante "a" gera o determinante "b" (MORIN, 2011a). Mas este autor não enxerga o complexo na visão unidirecional da realidade e propõe pensar a causa-efeito a partir do princípio da recursividade, pois não há fenômeno de causa única e por mais que pareçam lineares, estas são não-lineares: os efeitos retroagem sobre as causas e as realimentam. Este autor utiliza um exemplo para esclarecer essa não-linearidade:

Assim, nós, indivíduos, somos os produtos de um sistema de reprodução que vem do início dos tempos, mas esse sistema não pode se reproduzir se nós mesmos não nos tornarmos produtores com o acasalamento (MORIN, 2014, p. 95).

E finalmente o princípio hologramático que conduz o pensamento através do entendimento de que "não apenas a parte está no todo, mas o todo está na parte" (MORIN, 2011a). Ou seja, a parte está no todo, da mesma forma que o todo está na parte. Esta ideia vai além do pensamento simplificador, que contempla apenas partes, por meio da visão linear, simplista e fechada, e também do holismo, que abrange o todo e nega as especificidades. O princípio hologramático pode ser comparado a plasticidade cerebral. BASTOS \& ALVES (2013), esclarecem que a plasticidade cerebral:

É uma propriedade inerente ao sistema nervoso com a capacidade de modificar o seu funcionamento e de se reorganizar através de alterações ambientais ou de lesão (BASTOS \& ALVES, 2013, p. 51).

A realidade não pode ser apreendida a partir de fenômenos isolados, assim como o funcionamento cerebral não pode ser reduzido e fixado em pontos específicos do cérebro ou em grupos isolados de células. A realidade é, isso sim, organizada, desorganizada e reorganizada a partir da ação de fenômenos que atuam de forma articulada. E ao evidenciar no sistema nervoso uma organização dinâmica e aberta, denominada plasticidade cerebral, sendo que as partes estão incluídas no todo como o todo está imerso em cada parte de uma forma dinâmica. Assim sendo, para compreender o real deve-se considerar que somente é possível definir uma parte como tal, em relação a um todo (MORIN, 2014). 
Segundo MORIN (2011a) não é possível apreender complexidade da realidade a partir da disjunção, sendo assim esses princípios não podem ser vistos separados e sim interdependentes, ou seja:

[...] na lógica recursiva, sabe-se muito bem que 0 adquirido no conhecimento das partes volta-se sobre o todo. $\mathrm{O}$ que se aprende sobre as qualidades emergentes do todo, tudo que não existe sem organização voltase sobre as partes. Então pode-se enriquecer o conhecimento das partes pelo todo e do todo pelas partes, num mesmo movimento produtor de conhecimentos (MORIN, 2011).

Portanto, MORIN (2011a) alerta que a compreensão do todo em seu dinamismo suplanta ao mero entendimento das partes, pois o todo está nas partes como as partes estão no todo. $E$ ainda esclarece que a interdependência dos princípios dialógico, recursivo e hologramático apresenta condições de (r)estabelecer as articulações para compreensão dos diversos elementos constituintes de um fenômeno e o dinamismo no qual está inserido.

\section{A FORMAÇÃO DE PROFESSORES DE BIOLOGIA, A COMPLEXIDADE E O DESAFIO DA TRANSDISCIPLINARIDADE}

Quando discute-se sobre o modelo de ensino e suas consequências, não se pode deixar de incluir nas discussões a fragilidade na formação inicial dos "futuros" profissionais em educação, que deverão se apropriar do desafio de aprender o que ensinarão e tentar ensinar o que aprenderam. A ênfase em futuro é uma tentativa de assinalar os índices alarmantes de desistência da carreira, explicados também pela falta de atrativos, durante cursos de licenciatura e até após a graduação (PIOLLI, 2015).

As formações: básica e superior ainda são centradas na percepção disciplinar. Esse fato se consolida como um grande desafio, segundo MORIN (2001), quem vai educar os educadores? E ainda dentro dessa problemática, como formar o sujeito do aprendizado se o formador tem essa lacuna em sua formação? Assim chega-se a um impasse, no qual não se pode ter a ingenuidade em crer na existência de um "caminho" único e definitivo para minar esses problemas, pois a educação não está em crise, como defendem os reducionistas, e sim em policrise, como pontua MORIN (2011c) "Um componente invisível da policrise é a crise do pensamento". E cientes disso, deve-se pensar, discutir, repensar e rediscutir para tentar entender a complexidade dentro da precariedade educacional antes alardear um caminho simples, e até mágico, para uma reviravolta nesse quadro.

ANDRADE (2011) considera que a estrutura curricular dos cursos de graduação das Licenciaturas em Ciências (Biologia, Física e Química) ainda é organizada por disciplinas específicas e que esta organização acaba por convergir em uma precoce especialização já na formação inicial. E que isto se reflete na visão de Ciência dos futuros professores e pesquisadores, que não sabem relacionar o conhecimento específico com o conhecimento geral da ciência e nem com outras subáreas da ciência.

A autora ainda considera que nos cursos de Ciências Biológicas, em especial, o conhecimento biológico é o reflexo do desenvolvimento dessa ciência fragmentada e particionada, bem como vários conceitos importantes e fundamentais para a Biologia, como o do próprio objeto de estudo da biologia, o ser vivo, acabam por exercer papéis secundários na formação docente. Sob essa perspectiva, MORIN 
(2014, p. 32) considera que "as ciências biológicas progridem em múltiplas frentes, mas essas frentes não estão coordenadas umas às outras e levam à ideias divergentes", o que se torna extremamente danoso, em especial, para o indivíduo que se encontra na formação inicial.

Considerando a necessidade de entender as fragilidades na formação dos professores de Biologia deve-se pensar inicialmente na compreensão do processo de construção do conhecimento biológico, e para BERTONI \& LUZ (2011), o objeto de estudo da Biologia, como em outras áreas das ciências, sofre influências determinantes para sua construção, e isso fica evidente quando diz:

\begin{abstract}
Na História da Biologia percebemos que o objeto de estudo sempre esteve ligado ao fenômeno vida, influenciado pelo pensamento historicamente construído, correspondente à concepção de ciência de cada época e à maneira metódica de conhecer a natureza. Desde a Antiguidade até a contemporaneidade, esse fenômeno foi entendido de diversas maneiras, conceituado tanto pela filosofia natural quanto pelas ciências naturais, de modo que se tornou referencial na construção do conhecimento biológico e na criação de modelos interpretativos do fenômeno vida. (BERTONI \& LUZ, 2011).
\end{abstract}

Essa realidade aponta a necessidade de repensar conceitos e principalmente as estratégias utilizadas na formação dos professores da Biologia, pois MOREIRA (2004) argumenta que a educação em ciências deve estimular a construção e reconstrução de significados e possibilitar o compartilhamento desses no contexto das ciências, ou seja, interpretar o mundo desde o ponto de vista das ciências, manejar alguns conceitos, leis e teorias científicas, abordar problemas raciocinando cientificamente, identificar aspectos históricos, epistemológicos, sociais e culturais das ciências. Para CORRÊA et al. (2008), é importante contextualizar os momentos históricos e os possíveis condicionantes socioculturais, os quais contribuíram para os avanços do conhecimento biológico.

O currículo dos cursos de Ciências Biológicas, em geral, é formado por blocos de disciplinas isoladas, não havendo a integração do conhecimento aprendido e nem discussões sobre a História, Filosofia da Ciência e nem da Epistemologia do conhecimento biológico, sendo que este se caracteriza pela compreensão de fenômenos em uma complexa rede de interações, aos quais perdem o sentido com a ampla divisão.

O estudo das ciências biológicas em subáreas sem estudos e discussões epistemológicas, faz com que se perca a noção da totalidade do conhecimento e da própria biologia enquanto ciência (ANDRADE, 2011), uma vez em que são analisados aspectos isolados, sem contextualizações históricas, epistemológicas, conceituais, filosóficas e práticas integradoras, condicionando o futuro professor de biologia ao que MORIN (2014) chama de hiperespecialização, tolhendo-lhe logo cedo o uso da inteligência geral e das aptidões gerais e integradoras. Este autor ainda coloca que ao contrário do que se pensa e se tem difundido, as aptidões gerais da mente favorecem o desenvolvimento das competências particulares e especializadas e não o contrário, todavia o aprimoramento da inteligência geral deve estar ligado a dúvida, incluindo-se aí, a lógica, a dedução, a indução, a argumentação e a discussão.

Nesse contexto, ISKANDAR \& LEAL (2002) observam que "As matérias de formação geral são fundamentais para as matérias profissionalizantes. Não seria exagero dizer que aquelas podem servir de substrato para estas". No entanto, não é 
isso o que tem observado em boa parte da matriz curricular dos cursos de biologia, nos quais privilegiam-se as partes em detrimento do todo, ou seja, o saber especializado preferencialmente ao geral.

Essa educação moldada no ideário positivista inibe a formação do espírito crítico, o que acaba tendo como consequência perdas consideráveis em termos de conhecimento científico, conceitual e geral da ciência. Em razão disso, há a necessidade de mudanças no processo de formação de professores, para estes, no exercício da prática pedagógica, não se constituam como meros reprodutores do ensino compartimentado e descontextualizado (NASCIMENTO \& MARTINAZZO, 2008), que tem se estabelecido nos cursos de Biologia. Sob esse aspecto MORAES (2007) considera que:

\footnotetext{
Para penetrar no campo do sagrado, com sua intuição, sensibilidade e imaginação, o formador precisa saber articular e reconhecer a existência de outros tipos de conhecimento e de outras realidades, nos quais a racionalidade, simplificadora e fragmentadora do conhecimento, dificulta sua percepção e compreensão, dificultando a elaboração das devidas respostas. É dentro deste arcabouço conceitual que precisamos também repensar a formação docente (MORAES, 2007, p. 36).
}

Nesse mesmo sentido MORIN (2011b) considera como sendo urgente transpor o pensamento reducionista, que distorce a realidade, gerando o empobrecimento e realizar uma transformação profunda na busca por um pensamento contextualizado, global, multidimensional e complexo, que contemple melhor a complexidade da realidade e se contraponha as contradições e a linearidade do conhecimento. No que se refere à biologia, o mundo dos seres vivos possui sua complexidade específica (CARVALHO \& GUAZZELLI, 2005).

Partindo-se dos pressupostos de mudança paradigmática defendidos por MORIN (2011b), considera-se necessária a criação de espaços que oportunizem o diálogo entre diferentes frentes disciplinares na biologia. Para PETRAGLIA (2008) dialogar não pressupõe um consenso de ideias ou opiniões, mas uma convivência entre os opostos, em um debate saudável e ético, no qual a geração do conflito propicia o surgimento de novos pensamentos, caminhos e paradigmas e que este diálogo entre visões conflitantes é capaz de promover a religação de características e qualidades. Neste sentido, MORAES (2007) pontua que:

\footnotetext{
Primeiramente, é necessário criar espaços e condições [...] para a vivência de processos mais integrados e integradores de aprendizagem, processos que resgatem a inteireza, a autoreferencialidade e a multidimensionalidade do docente/aprendiz/formador. Isso requer processos de formação diferenciados e trabalhados a partir de metodologias transdisciplinares que levem o docente a transcender a dualidade presente no nível de realidade em que ele se encontra.
}

Surgindo, então, como uma proposta para a mudança na formação de professores de Biologia, a transdisciplinaridade, que segundo NICOLESCU (1999) "[...] como o prefixo 'trans' indica, diz respeito aquilo que está ao mesmo tempo entre as disciplinas, através das diferentes disciplinas e além de qualquer disciplina".

Assim, a transdisciplinaridade na formação inicial de professores de biologia, não teria como proposição a criação de uma disciplina única e exclusiva, como Didática de Ensino, Prática de Ensino, Filosofia ou Sociologia da Biologia, mas sim oportunizar a formação de um docente transdisciplinar, formado a partir de vivências 
mais integradoras, que sejam capazez de perceber a complexidade por trás de eventos, fenômenos e processos, compreendendo a dinâmica existente entre os diferentes níveis de realidade (MORAES, 2007) que não são atendidos pelo pensamento simplificador.

O currículo engessado dos cursos de graduação das licenciaturas de biologia, no qual as disciplinas não dialogam, com práticas de estágio distanciadas da realidade escolar, direcionados sob aspectos extremamente burocráticos e rígidos não tem conseguido captar as nuances presentes no ato social de educar e tampouco tem contribuído para uma identidade inovadora no docente (PIMENTA, 1997). Conforme MORIN (2001), a Universidade tem importante papel sobre as mudanças sociais, esta "conserva, memoriza, integra, ritualiza uma herança cultural dos saberes, ideias, valores, regenera essa herança ao reexaminá-lo, atualizá-lo e gera saberes, ideias e valores que passam a fazer parte dessa herança". Desta forma, para que se consiga uma mudança no perfil formativo de professores e em sua futura prática pedagógica, é necessário que haja uma mudança estrutural curricular nas licenciaturas de biologia, dando ênfase aos enfoques transdisciplinares e ao diálogo entre suas áreas e subáreas, buscando a unidade do conhecimento científico e a própria compreensão das Ciências Biológicas, prejudicada pela fragmentação disciplinar cartesiana, centrada na hiperespecialização.

Conforme afirma NICOLESCU (1999) o homem tomou o conhecimento de todas as disciplinas, sem, no entanto, obter a sua plenitude e totalidade. Como forma de superar esse paradigma, a educação do futuro deve procurar corrigir e identificar as causas e origens dos erros e ilusões vigentes. Sendo para tanto, primordial munir-se de conhecimentos mais amplos, como características culturais, mentais, etc. e também formar um docente que leve em consideração a condição humana, fundamental para o ensino, uma vez que todo ser humano é um todo, físico, biológico, psíquico, cultural, social e histórico (OLIVEIRA et al., 2016). E que este compreenda a natureza complexa do conhecimento, com vários olhares guiados na mesma direção e que ao mesmo tempo são opostos e complementares. "E é desse pluralismo de ideias que a própria transdisciplinaridade se nutre. E da religação dos diversos tipos de pensamento é que se constitui o pensamento complexo" (PETRAGLIA, 2008, p. 42).

A produção e disseminação do conhecimento requerem um novo modo de pensar, um pensamento complexo e transdisciplinar na construção de saberes, e que este seja capaz de mobilizar o cientista-cidadão a intervir na história (ALMEIDA, 2011), assim, essa mudança deve começar nas bases, na formação inicial dos professores. No que se refere à biologia, a complexidade e a transdisciplinaridade ainda se constituem como desafios a serem alcançados e anseios a serem realizados em sua plenitude.

\section{CONSIDERAÇÕES FINAIS}

Edgar Morin é um dos mais importantes estudiosos da complexidade e suas aplicações reais para a vida prática, sempre apontando a necessidade de uma reforma do pensamento e, por consequência, a reforma de ensino. Claro que para que isso ocorra é necessário que hajam rupturas e quebra de paradigmas para a apropriação do conhecimento. Morin enfatiza em seus escritos que uma educação mais libertária e qualitativa é necessária, mas antes de tudo é preciso pensar a complexidade e principalmente extinguir essa visão linear e reducionista de mundo. 
As práticas educativas, de forma geral, trazem consigo um ensino fragmentado e descontextualizado, onde prioriza-se os conteúdos e ignora-se as habilidades e valores inerentes do conhecimento. Fragmentar as disciplinas gera na educação um conhecimento baseado no pensamento simplificador, dificultando assim a visão de contexto, o conhecimento na totalidade. Vale ressaltar que não se trata da soma das partes para atingir o todo, mas da reaproximação que atenda a esse sistema complexo, que de certa forma exige uma relação mais dinâmica que possa determinar essa estruturação do todo.

O exercício do ato de educar insere-se em um contexto social, político, econômico, cultural e histórico, no qual vários aspectos são contraditórios e ao mesmo tempo complementares. As discussões sobre ciência na formação inicial de professores ao englobarem reflexões históricas, filosóficas, sociológicas e epistemológicas etc., possibilitam um diálogo entre os vários interlocutores e pontos de vistas diferentes, todavia ao ocorrerem isoladamente contribuem para a consolidação da fragmentação do conhecimento, uma ênfase na formação disciplinar, a mutilação dos saberes e, consequentemente, para o empobrecimento da formação docente, centrada nessa perspectiva positivista.

A biologia, assim como outras áreas do conhecimento, também acabou por herdar e manter a forma cartesiana de ensino, com grandes números de disciplinas, cada uma com suas especificidades e campos de atuação. Na formação de professores de biologia essa é uma prática usual nas universidades e que surtirá reflexos no trabalho do professor formado nesse modelo de ensino. Muitas vezes o professor ao exercer a prática apresenta dificuldades em trabalhar com projetos inovadores e transdisciplinares, por já estar habituado com a fragmentação do conteúdo, ficando difícil que este saiba, ou tenha interesse, na conexão entre os saberes. E como consequência, os alunos também acabam por ter um ensino fragmentado, onde cada disciplina tem espaço isolado e não é feita nenhuma ligação entre estes, reforçando assim a ideia da hiperespecialização, veementemente combatida por Morin.

A oportunização de discussões críticas sobre didática, mudança conceitual, paradigmas de ensino, currículo, ciência, epistemologia, cultura científica, ética, afetividade, pluralidade de ideias e outra infinidade de temas, ocorrendo em um debate saudável durante a graduação pode possibilitar ao futuro professor de biologia uma formação mais ampla e complexa. Todavia, se faz necessário considerar que a inserção dessas temáticas deve ser feita de forma articulada nas disciplinas e não apenas através de uma disciplina isolada que trabalhe cada um desses temas. Além disso, a prática pedagógica em si deve ser tratada também pelas disciplinas de áreas específicas, como a morfologia, a genética, a botânica, a fisiologia etc. e que estas dialoguem entre si favorecendo a compreensão da complexidade das ciências biológicas e a formação de um professor na complexidade da ciência e na transdisciplinaridade e não provocando a cisão prematura dos saberes, direcionando o sujeito à prematura especialização.

Consideramos que o processo de formação docente depende da vivência tida pelo profissional nos ambientes de aprendizagem, assim, observamos que a formação em biologia está diretamente ligada ao tipo de formação inicial do docente, do currículo proposto pela faculdade e também do corpo de professores que ministra as disciplinas. Um currículo baseado na transdisciplinaridade e complexidade, aliado a professores portadores de espírito científico e que são capazes de propiciar espaços para discussões, críticas e reflexões sobre a ciência que se ensina, sobre 
os conceitos fundantes, sobre a prática docente e, principalmente, que saibam interligar os saberes e estimular a unidade do conhecimento contribuem muito para que a ruptura paradigmática do ensino, proposta por Morin.

O ensino voltado para a complexidade requer do docente uma intensa reflexão sobre as práticas, tanto profissionais quanto da vida social. Tarefa esta não fácil, visto que exige uma disponibilidade de tempo muitas vezes limitada pelos próprios afazeres. Pensar na formação de professores mais críticos que atendam a relação indivíduo/espécie/sociedade não pode mais ser ignorada, pois os educadores e formadores podem auxiliar nesse processo de transformação da sociedade e são peças fundamentais na transformação e apropriação dos saberes. Antes de mais nada, faz-se necessária a criação de um ambiente favorável a essa reflexão, e destacamos a vivência de processos mais integradores que os auxiliem nesse resgate da totalidade. Claro que isso requer maiores esforços dos centros de formação, na promoção de trabalhos diferenciados e até mesmo transdisciplinares que levem o professor a reconhecer a complexidade que existe por trás do que lhe está sendo ensinado.

A transdisciplinaridade representa um nível de integração e interconexão disciplinar que poderá auxiliar o professor em formação a superar essa visão de dualidade aplicada a esse paradigma conservador vigente, que o impede de perceber que ensinar vai muito além de simplesmente reproduzir conteúdo e modelos biológicos. A transdisciplinaridade exige atuação tanto de professores criativos em metodologias, que proporcionem a formação de um aluno crítico e autônomo, quanto dos capazes de propiciar a religação entre os saberes das diferentes disciplinas. Estes são desafios que se consolidam no cotidiano acadêmico e que necessitam ser compreendidos e ultrapassados para a melhoria da formação inicial e, muitas vezes, deficitária dos docentes de biologia, numa atitude verdadeiramente transformadora e de superação do paradigma clássico vigente, rumo à complexidade do pensamento dos responsáveis pelos processos de Ensino e Aprendizagem e da Pesquisa nas Ciências Biológicas.

\section{REFERÊNCIAS}

ALMEIDA, M. C. Prefácio. In: HENRIQUE, A. L. S.; SOUZA, S. C. (Org.). Transdisciplinaridade e Complexidade: uma nova visão para a educação no século XXI. Natal: Editora do CEFET-RN, p. 07- 10. 2005.

ANDRADE, M. A. B. S. A epistemologia da biologia na formação e pesquisadores: compreensão sistêmica de fenômenos moleculares. Bauru, 2011. 210 f. Tese (Doutorado em Educação para Ciência) - Universidade Estadual Paulista.

AZEVEDO, R. O. M., GHEDIN, E., SILVA-FORSBERG, M. C., \& GONZAGA, A. M. Formação inicial de professores da educação básica no Brasil: trajetória e perspectivas. Revista Diálogo Educação, Curitiba, 12(37), 997-.1026, 2012. Disponível em: <doi:10.7213/dialogo.educ.7214>.

BEHRENS, M. Docência universitária no paradigma da complexidade: caminho para visão transdisciplinar. In: MAGALHÃES, S. M. O. e SOUZA, R. C. C. R. de (org). Formação de Professores: Elos da dimensão complexa e transdisciplinar. Goiânia: Liber Livros, 2012. 
BEHRENS, M. A.; RODRIGUES, D. G.. Paradigma emergente: um novo desafio. Pedagogia em Ação, v. 6, n. 1, 2014. Disponível em: <http://periodicos.pucminas.br/index.php/pedagogiacao/article/view/9233/7685>.

BASTOS, L. S.; ALVES, M. As influências de Vygotsky e Luria à neurociência contemporânea e à compreensão do processo de aprendizagem. Revista Práxis, v. 5, n. 10, 2013. Disponível em: <web.unifoa.edu.br/praxis/numeros/10/41-53.pdf>.

BERTONI, D.; ASINELLI-LUZ, A. Os estilos de pensamento biológico sobre o fenômeno vida. Revista Contexto \& Educação, v. 26, n. 86: p. 23-49, jul./dez. $2011 . \quad$ Disponível em: <https://www.revistas.unijui.edu.br/index.php/contextoeducacao/article/view/271>.

BITTAR, M.; DA SILVA, M. R.; HAYASHI, M. C. P. I. "Produção científica em dois periódicos da área de educação." Avaliação: Revista da Avaliação da Educação Superior v. 16, n. 3, 2011. Disponível em: $<$ http://periodicos.uniso.br/ojs/index.php?journal=avaliacao\&page=article\&op=view\&p ath $\% 5 \mathrm{~B} \% 5 \mathrm{D}=910>$.

CARVALHO, W.; GUAZZELLI, I. R. B. A educação biológica frente à cultura globalizada. Revista Enseñanza de las ciencias, n.extra, 2005.Disponível em: <https://ddd.uab.cat/pub/edlc/edlc_a2005nEXTRA/edlc_a2005nEXTRAp5edubio.pdf>.

CORRÊA, A. L.; SILVA, P. R.; MEGLHIORATTI, F. A.; CALDEIRA, A. M. A. Aspectos históricos e filosóficos do conceito de vida: contribuições para o ensino de biologia. Filosofia e História da Biologia, v. 3, p. 21-40, 2008. Disponível em: <http://www.abfhib.org/FHB/FHB-03/FHB-v03-02-Andre-Correa-et-al.pdf>.

GATTI, B. A. A formação inicial de professores para a educação básica: as licenciaturas. Revista USP, n. 100, p. 33-46, 2014. Disponível em: <http://dx.doi.org/10.11606/issn.2316-9036.v0i100p33-46>.

GEMIGNANI, E. Y. M. Y. Formação de professores e metodologias ativas de ensinoaprendizagem: ensinar para a compreensão. Fronteiras da Educação, v. 1, n. 2, 2012.

Disponível

em:

<http://www.fronteirasdaeducacao.org/index.php/fronteiras/article/view/14>.

HOBSBAWM, E. Feiticeiros e aprendizes - as ciências naturais. In: A Era dos Extremos - o breve século XX - 1914-1991. São Paulo: Companhia das Letras, 2015.

ISKANDAR, J. I.; LEAL, M. R. Sobre positivismo e educação. Revista Diálogo Educacional, Curitiba, v. 3, n.7, p. 89-94, set./dez. 2002. Disponível em: <http://www2.pucpr.br/reol/index.php/DIALOGO?dd1=654\&dd99=pdf>.

LISPECTOR, C. A descoberta do mundo. Lisboa: Relógio D'Água, 2013. 
MORAES, M. C. A Formação do educador a partir da complexidade e da transdisciplinaridade. Revista Diálogo Educacional, Curitiba, v. 7, n. 22, p.13-38, set./dez. $2007 . \quad$ Disponível em: $<$ http://www2.pucpr.br/reol/index.php/dialogo?dd99=pdf\&dd1=1571>.

MOREIRA, M. A. A pesquisa básica em educação em ciências: uma visão pessoal. In: Revista Chilena de Educacion Cientifica, 3(1), p. 10-17, 2004. Disponível em: <http://www.if.ufrgs.br/ moreira/Pesquisa.pdf>. Acesso em 9 jul. 2016.

MORIN, Edgar. A cabeça bem-feita: repensar a reforma, reformar o pensamento. 21. ed. Rio de Janeiro: Bertrand Brasil, 2014

2011a.

Introdução ao Pensamento Complexo. 4. ed. Porto Alegre: Sulinas,

.Os setes saberes necessários à educação do futuro. 2. ed. São Paulo: Cortez, 2011b.

A minha esquerda. 1. ed. Porto Alegre: Sulinas, 2011c.

NASCIMENTO, L. A.; MARTINAZZO, C. J. A Formação de Professores na Contemporaneidade: Desafios e Perspectivas. In: ANPEDSUL, VII Seminário de Pesquisa em Educação da região sul , 2008, Itajaí. Anais....tajaí: UNIVALI, 2008. p. 1-14

NICOLESCU, B. O Manifesto da Transdisciplinaridade. São Paulo: Triom, 1999.

OLIVEIRA, A. V.; SANCHES, B. A; SILVA, L. F. A. Complexidade, currículo e ensino: uma reflexão sobre a licenciatura. Revista Educação, Cultura e Sociedade,Sinop, v. $6, \quad$ n. 1 , p. 233- 244, jan./jun. 2016. Disponível em: <sinop.unemat.br/projetos/revista/index.php/educação/article/download/2149/1681 >.

PETRAGLIA, I. Interdisciplinaridade e Transdisciplinaridade: religando saberes no espaço escolar. In: ALMEIDA, C. e PETRAGLIA, I. Estudos da Complexidade 2. São Paulo: Xamã, 2008.

Edgar Morin: A Educação e a Complexidade do Ser e do Saber. $12^{\mathrm{a}}$ ed. Petrópolis/RJ: Vozes, 2011.

PIMENTA, S. G. Formação de professores: saberes da docência e identidade do professor. Nuances - v.lll- Set/1997. Disponível em: <http://dx.doi.org/10.14572/nuances.v3i3.50>.

PIOLLI, E. A valorização docente na perspectiva do plano nacional de educação (PNE) 2014-2024. Cadernos Cedes 35.97, 483-491, 2015. Disponível em: <http://dx.doi.org/10.1590/CC0101-32622015155703>.

SILVA, A. C.; INFANTE-MALACHIAS, M. E. Reflexões sobre a convergência do Pensamento de Paulo Freire e de Edgar Morin: Contribuições para a Formação 
docente. Cadernos de Educação (UFPel), v. 42, p. 223-242, 2012. Disponível em: <https://periodicos.ufpel.edu.br/ojs2/index.php/caduc/article/view/2155/1972>.

SILVA, L. M.; BRIZOLLA, F.; DA SILVA, L. E. Projeto pedagógico do curso de licenciatura em Ciências da UFPR Litoral: desafios e possibilidades para uma formação emancipatória. Revista Brasileira de Estudos Pedagógicos v. 94, n. 237, 2013.

Disponível em:

<http://www.rbep.inep.gov.br/index.php/rbep/article/view/376/367>. 